\title{
Functional dissection of translocon proteins of the Salmonella Pathogenicity Island 2-encoded type III secretion system
}

\author{
Stefanie U Hölzer and Michael Hensel*
}

\begin{abstract}
Background: Type III secretion systems (T3SS) are essential virulence factors of most Gram-negative bacterial pathogens. T3SS deliver effector proteins directly into the cytoplasm of eukaryotic target cells and for this function, the insertion of a subset of T3SS proteins into the target cell membrane is important. These proteins form heterooligomeric pores acting as translocon for the delivery of effector proteins. Salmonella enterica is a facultative intracellular pathogen that uses the Salmonella Pathogenicity Island 2 (SPI2)-encoded T3SS to manipulate host cells in order to survive and proliferate within the Salmonella-containing vacuole of host cells. Previous work showed that SPI2encoded SseB, SseC and SseD act to form the translocon of the SPI2-T3SS.
\end{abstract}

Results: Here we investigated the structural requirements of SseB and SseD to form a functional translocon. Based on bioinformatic predictions, deletional analyses of SseB and SseD were performed and the effect on secretion by the T3SS, formation of a translocon, translocation of effector proteins and intracellular replication was investigated. Our data showed that both SseB and SseD are very sensitive towards alterations of the primary structure of the proteins. Although proteins encoded by mutant alleles were still secreted, we observed that all mutations resulted in a loss of function of the SPI2-T3SS.

Conclusion: These observations indicate that translocon proteins of the SPI2-T3SS are highly evolved towards the formation of multi-subunit complex in the host cell membrane. Structural alterations are not tolerated and abrogate translocon function.

\section{Background}

Gram-negative bacteria have evolved various mechanisms for the transport of proteins across the bacterial envelope. Among these, type III secretion systems (T3SS) and type IV secretion systems are of specific interest since these systems mediate the vectorial transport of effector proteins into eukaryotic target cells [reviewed in [1]]. This process is termed translocation and requires the contact of the bacteria to a host cell membrane. T3SS are involved in a variety of bacteria-host cell interactions, ranging from symbiosis to pathogenesis [2]. Pathogenic bacteria deploy T3SS to translocate effector proteins with toxin-like activities and can manipulate various host cell functions by means of these effectors. Salmonella enter$i c a$ is a facultative intracellular pathogen that has devel-

\footnotetext{
* Correspondence: Michael.Hensel@biologie.uni-osnabrueck.de

1 Mikrobiologisches Institut, Universitätsklinikum Erlangen, Erlangen, Germany Full list of author information is available at the end of the article
}

oped a unique intracellular lifestyle. Salmonella uses two distinct T3SS during different phases of pathogenesis [3]. The Salmonella Pathogenicity Island 1 (SPI1)-encoded T3SS mediates invasion of non-phagocytic cells and triggers inflammatory responses [reviewed in [3]].

During the intracellular phase of pathogenesis, Salmonella resides within a specific organelle of the host cell, the so-called Salmonella-containing vacuole or SCV. The biogenesis of the SCV and the intracellular survival and replication critically depend on the function of virulence genes clustered within Salmonella Pathogenicity Island 2 (SPI2), a locus that encodes a second T3SS [4]. The expression of SPI2-T3SS genes is induced in intracellular Salmonella and expression is controlled by the SsrAB two-component system. So far, the factors sensed by this system are not known.

Translocation by the T3SS requires the contact to a membrane of the host cell. On the molecular level, it has 
been demonstrated that the contact actually results in insertion of a subset of T3SS proteins into the target cell membrane [5]. These proteins are secreted substrate proteins of the T3SS but do not enter the host cytoplasm but rather form a complex in the target cell membrane. The hetero-oligomeric complex leads to the formation of a pore or translocon through which effector proteins enter the target cell. The analyses of various T3SS indicated that translocons are commonly composed of three subunits belonging to protein super-families [reviewed in [6]]. SPI2-encoded proteins are most similar to the T3SS proteins of enteropathogenic E. coli (EPEC) and a close evolutionary relationship between the systems has been proposed. EPEC translocon proteins are termed Esp. The EspA family of proteins is involved in the formation of a filamentous structure linking the T3SS in the bacterial envelope to the translocon pore in the target membrane. The EspD family consists of highly hydrophobic proteins which are membrane integral with several transmembrane helixes. EspB is a further protein required for translocation and with its homologs considered to be part of the translocation pore [6].

Previous molecular and functional characterization has revealed that SseB (EspA family), SseC (EspD family) and SseD (EspB family) are secreted substrate proteins of the SPI2-T3SS and required for the translocation of effector proteins by intracellular Salmonella [7]. We could also demonstrate that SseB, SseC and SseD are not required for formation of needle-like appendages on Salmonella cells, but are involved in the translocon formation in infected host cells [8].

While the structure-function relationship of translocon subunits has been analyzed in greater detail for the T3SS of EPEC, Shigella spp. and Yersinia spp., only little is known about the translocon subunits of the SPI2-T3SS. In this work, we performed a functional dissection of SseB and SseD, two subunits of the translocon of the SPI2-T3SS. This analysis indicates that SseB and SseD are highly sensitive towards alteration of the primary structure. All predicted domains in $\mathrm{SseB}$ or $\mathrm{SseD}$ are required for the function as translocon subunit, while secretion by the SPI2-T3SS can still take place after deletion of various protein domains.

\section{Results}

\section{Deletional analyses of translocon proteins SseB and SseD}

Based on the previous observation that $\mathrm{SseB}, \mathrm{SseC}$ and $\mathrm{SseD}$ are required for the translocation of effector proteins by intracellular Salmonella [7], we started deletional analyses for the identification of functionally essential domains of the proteins. Here we focused on SseB and SseD.

Since SseB and SseD are most likely membrane-associated or integral proteins with hydrophobic character, the analysis of the hydrophobicity was a main consideration for the positions of deletions. In addition, coiled-coil domains are commonly found in substrate proteins of T3SS and have been shown as required for protein-protein interactions. The location of predicted coiled-coil domains in the sequence of SseB and SseD was also considered for the design of mutations.

The hydropathy plots, predictions of coiled-coil domains and the positions of deletions are displayed in Fig. 1A. Briefly, SseB $\Delta \mathrm{N} 1$ lacked the N-terminal aa residues 2-14 and $S s e B \Delta 1$ the N-terminal residues 15-30. $\mathrm{Sse} B \Delta 2$ was deleted for a hydrophobic region predicted as transmembrane region (aa 38-57), SseB $\Delta 3$ lacked the region containing coiled-coil domains (aa 58-90) and SseB $\Delta 4$ lacked both regions (aa 38-90). Constructs $\mathrm{SseB} \Delta 5$ and $\mathrm{SseB} \Delta 6$ were deleted for aa $91-115$ or aa 116 136 , respectively, both regions were without specific functional or structural predictions. Sse $\Delta 7$ was deleted for the putative chaperone binding site, i.e. aa 137-182. Finally, $\mathrm{SseB} \Delta \mathrm{C} 1$ was deleted for the C-terminal region of aa 183-196.

We observed that all deletion alleles led to the synthesis of corresponding proteins by a Salmonella sseB strain harboring the respective plasmids if grown under in vitro conditions inducing the expression of the SPI2 genes and the secretion of substrate proteins by the SPI2-T3SS (Fig. 2; see also Additional file 1). However, Western blot analyses indicated that the amounts of cell-associated SseB differed for the various deletion constructs. We also determined the proportion of SseB in the detached fraction, corresponding to secreted protein bound to surface appendages of Salmonella, and in the supernatant fraction corresponding to secreted proteins without association to the cell surface (Fig. 2). For Salmonella WT, a large proportion of secreted SseB was found in the detached fraction. No signal for SseB was observed for the $s s e B$ strain. An $s s e B$ strain complemented with psseB showed an equal distribution of secreted $\mathrm{SseB}$ in the detached and supernatant fraction and the distribution observed for this strain would be relevant for comparison to $s s e B$ strains harboring plasmids for the expression of various deletion constructs. We observed that $\operatorname{SseB} \Delta 4$, $\mathrm{Sse} B \Delta 5$ and $\mathrm{SseB} \Delta 6$ were not secreted or only present in secreted fractions in minute amounts. In addition, the amounts of SseB $\Delta 5$ and SseB $\Delta 6$ were highly decreased in comparison to the WT or the complemented strains and signals in Western blots were only detected after extended exposure times. SseB $\Delta 1$ was only detected in the detached fraction but not the secreted fraction. The situation was opposite for SseB $\Delta 2$, which was only present in the supernatant fraction but not in the detached fraction. Control Western blots for DnaK indicated that low amounts of this cytoplasmic protein were present in the detached fraction, thus the amounts of SseB in the 
A)

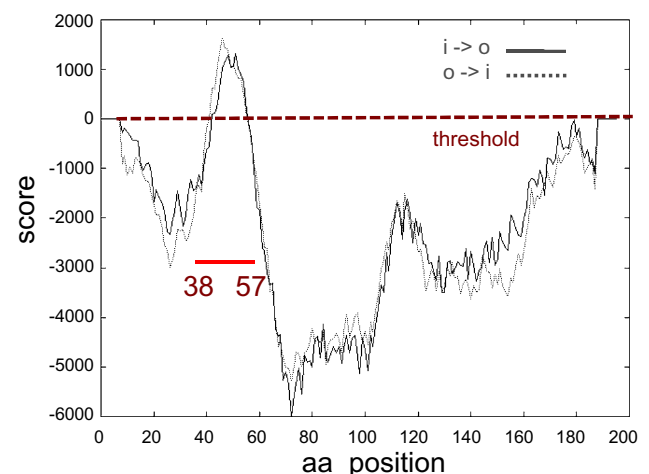

B) coiled-coil domain prediction

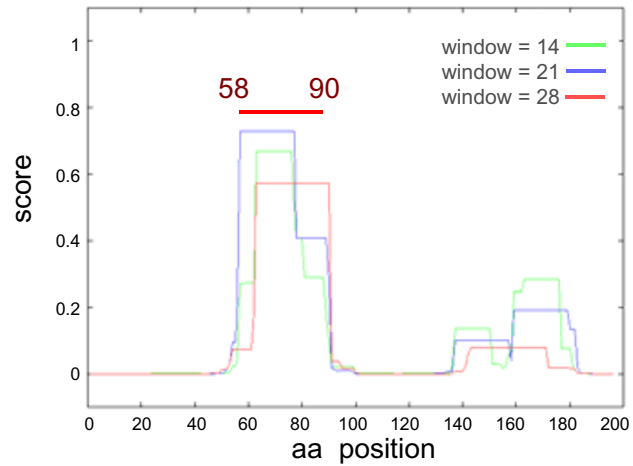

C) coiled-coil chaperone binding

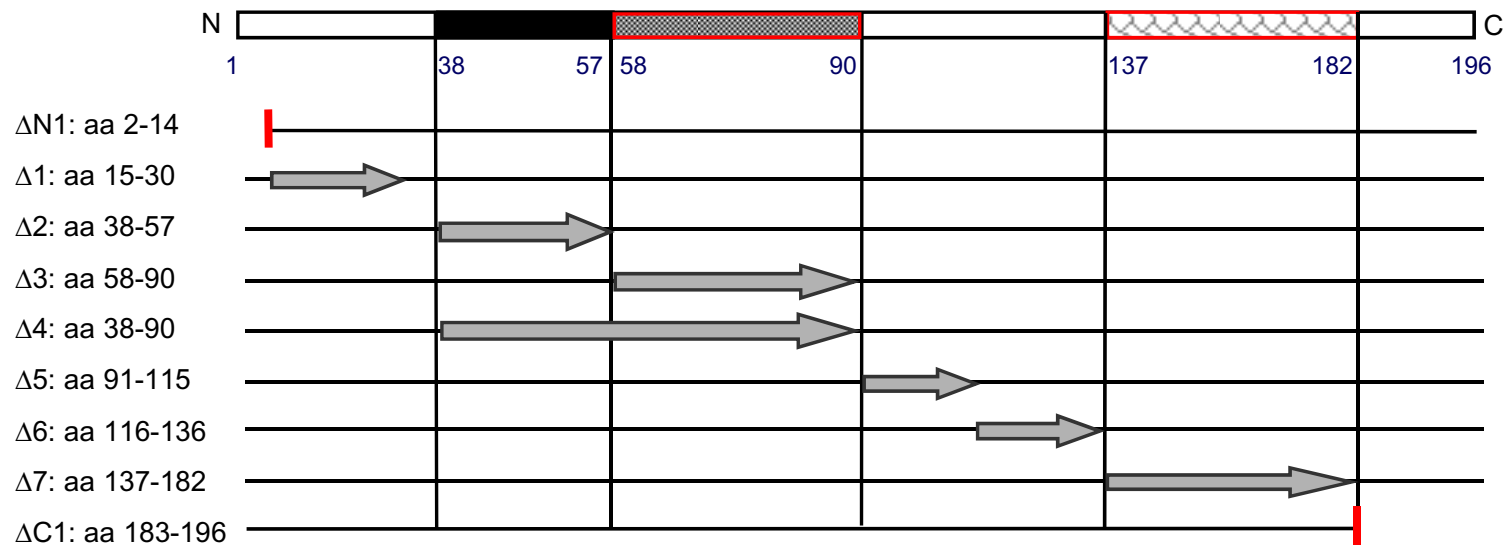

Figure 1 Bioinformatic analyses of SPI2 translocon protein SseB and characteristics of deletion variants of SseB. A) Using the program TMpred, putative transmembrane (TM) domains of the translocon protein SseB was predicted. o-i indicate the strongly preferred model, with $\mathrm{N}$-terminus outside (aa 38-57), i-o indicates the alternative model. B) Using the program COILS, coiled-coil regions in SseB were predicted. As output option the default parameters were selected that gave residue number, residue type and the frame and coiled-coil forming probability obtained in scanning windows of 14, 21 and 28 residues (as described on the Swiss EMBnet homepage). The region spanning aa 58-90 was considered as coiled-coil domain. C) Schematic representation of the amino acid sequence of wild-type SseB and positions of deletions analyzed in this study. The predicted TM domain, coiled-coil region, as well as the chaperone-binding site [10] are indicated. The deleted regions within SseB variants are indicated by arrows and C- or $\mathrm{N}$-terminal truncations are indicated by vertical red lines.

detached fraction of the $\mathrm{SseB} \Delta 1$ are likely to be the result of cell lysis. The secretion and partitioning of $\mathrm{SseB} \Delta 3$ and $\mathrm{SseB} \Delta \mathrm{C} 1$ was similar to that of WT SseB. For SseB $\Delta 7$ and $\mathrm{SseB} \Delta \mathrm{N} 1$, highly reduced secretion was observed and the larger proportion of the secreted protein was present in the supernatant fraction. These analyses indicate that synthesis and secretion was affected to a different extend by deletions and that secretion similar to WT is possible even with deletions of larger portions of the protein. The deletion of the coiled-coil domain had little effect on secretion and partitioning ( $\operatorname{Sse} B \Delta 3)$, while mutations affecting the putative transmembrane region abolished the secretion of the mutant variants of $\mathrm{SseB}(\mathrm{SseB} \Delta 2$ and SseB $\Delta 4)$. An SseB variant that lacked the postulated chaperone binding site in the $\mathrm{C}$-terminal region of $\mathrm{SseB}$ was still synthesized, but the amounts of this protein in the secreted fractions were highly reduced (SseB $\Delta 7$ ).

We then investigated the effect of the various deletions in SseB on the secretion of $\mathrm{SseC}$ and SseD and the partitioning of secreted SseC and SseD between the soluble and cell-bound fractions. For unknown reasons, larger amounts of DnaK were observed in the detached fraction of the $s s e B$ strain, but the mutation per se did not affect cell integrity since the complemented strains did not show increased release of cytosolic protein. In accordance with our previous report [7] we observed that the majority of SseD secreted by WT Salmonella is present in the detached fraction (Fig. 3). Strains expressing $s s e B \Delta 5$, 


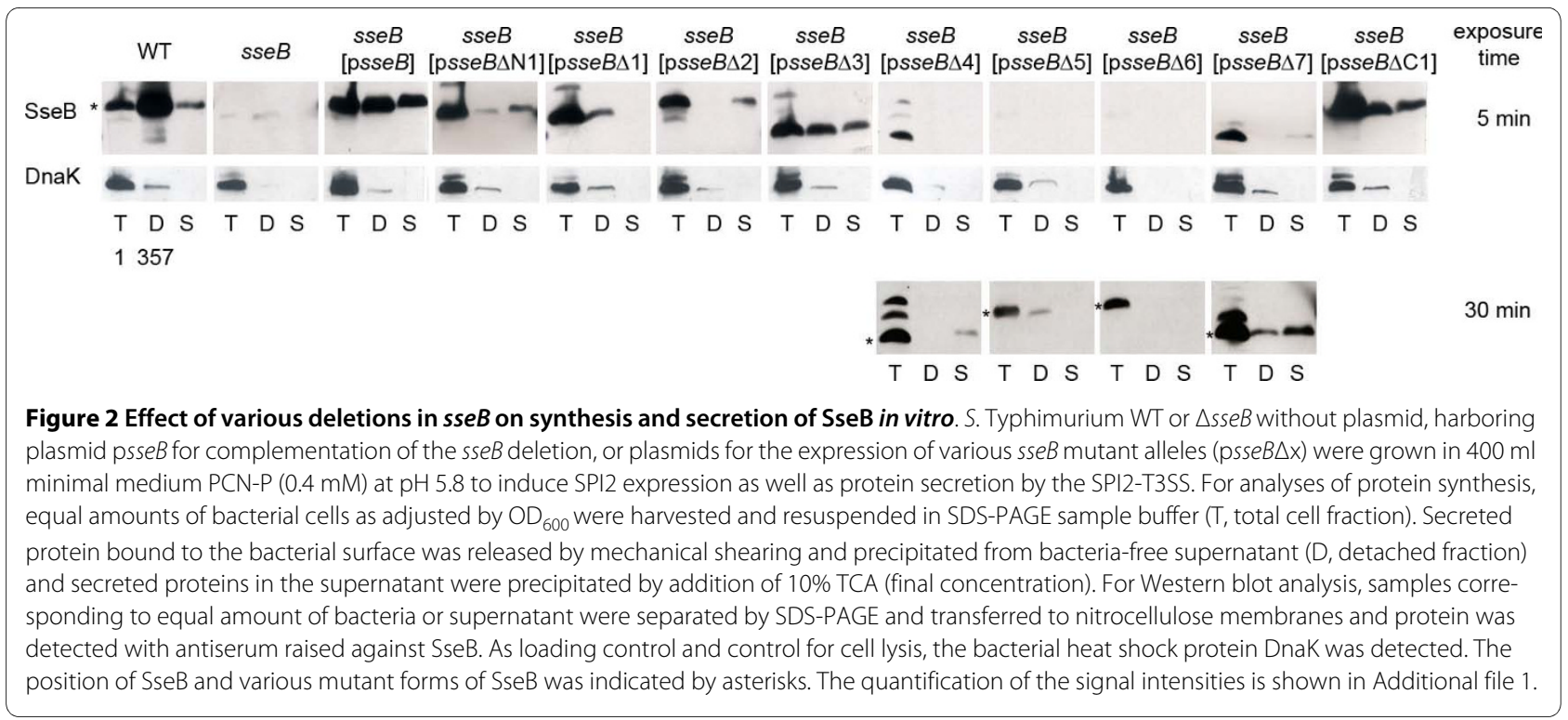

sse $B \Delta 6$ and, to a certain extend $s s e B \Delta 3$ resulted in reduced amounts of the secreted SseD in the supernatant fraction. The expression of the other deletion alleles of $s s e B$ resulted in the presence of secreted SseD in the culture supernatant as well as in the detached fraction (Fig. 3). Deletions in $s s e B \Delta 5, s s e B \Delta 6$ affect the binding site for SseA that acts as chaperone for SseB and SseD [9]. The altered partitioning observed for strains expressing these alleles may be due to the altered binding of chaperone SseA to its targets and altered stability of these proteins. The partitioning of SseD in the complemented sseB strain was different from that observed for the WT strain and most of SseD was present in the total cell fraction rather than in the detached fraction. This may be due to the over expression of $s s e B$ in the $s s e B$ [psseB] strain leading to more secretion of $\mathrm{SseB}$ in the supernatant and reduces the binding of SseB to the surface (compare Fig. 2). Therefore, the binding of SseD to the surface would be reduced and the release of SseD in the supernatant is increased. Most of the mutant alleles of $s s e B$ also resulted in higher amounts secreted SseD in the supernatant.

Similar effects were observed for the secretion and partitioning of $\mathrm{SseC}$ in strains expressing various alleles of sseB (data not shown).

\section{Effect of deletion of SseB domains on formation of translocon structures on Salmonella}

We have previously observed that secreted translocon proteins $\mathrm{SseB}$, SseC and SseD were predominantly located in surface structures that occurred in single or low copy number resulting in a punctuated staining in immune-fluorescence analyses $[7,8]$. To test the effect of deletions in SseB on the formation of such surface structures, we used immunofluorescence to analyze various strains grown under secretion-inducing culture conditions (Fig. 4). The treatment of cells with lysozyme prior to immuno-labeling allowed the estimation of the cytoplasmic pool of SseB variants (Fig. 4A). The staining intensities for SseB observed correlated well with the data

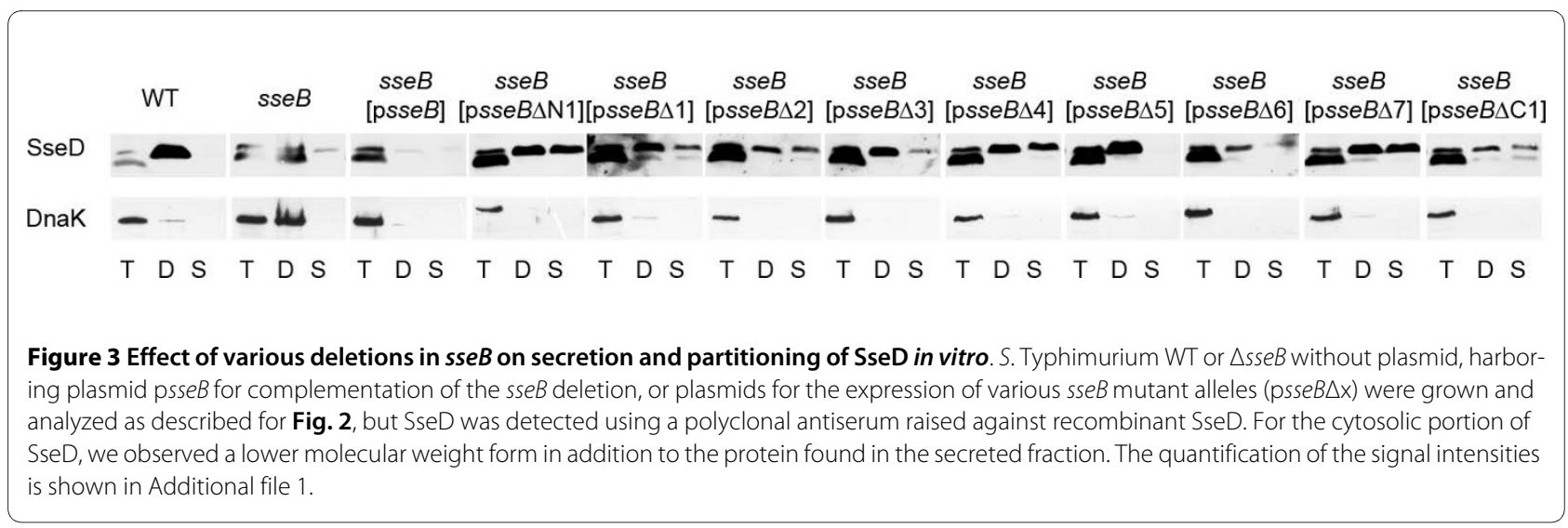




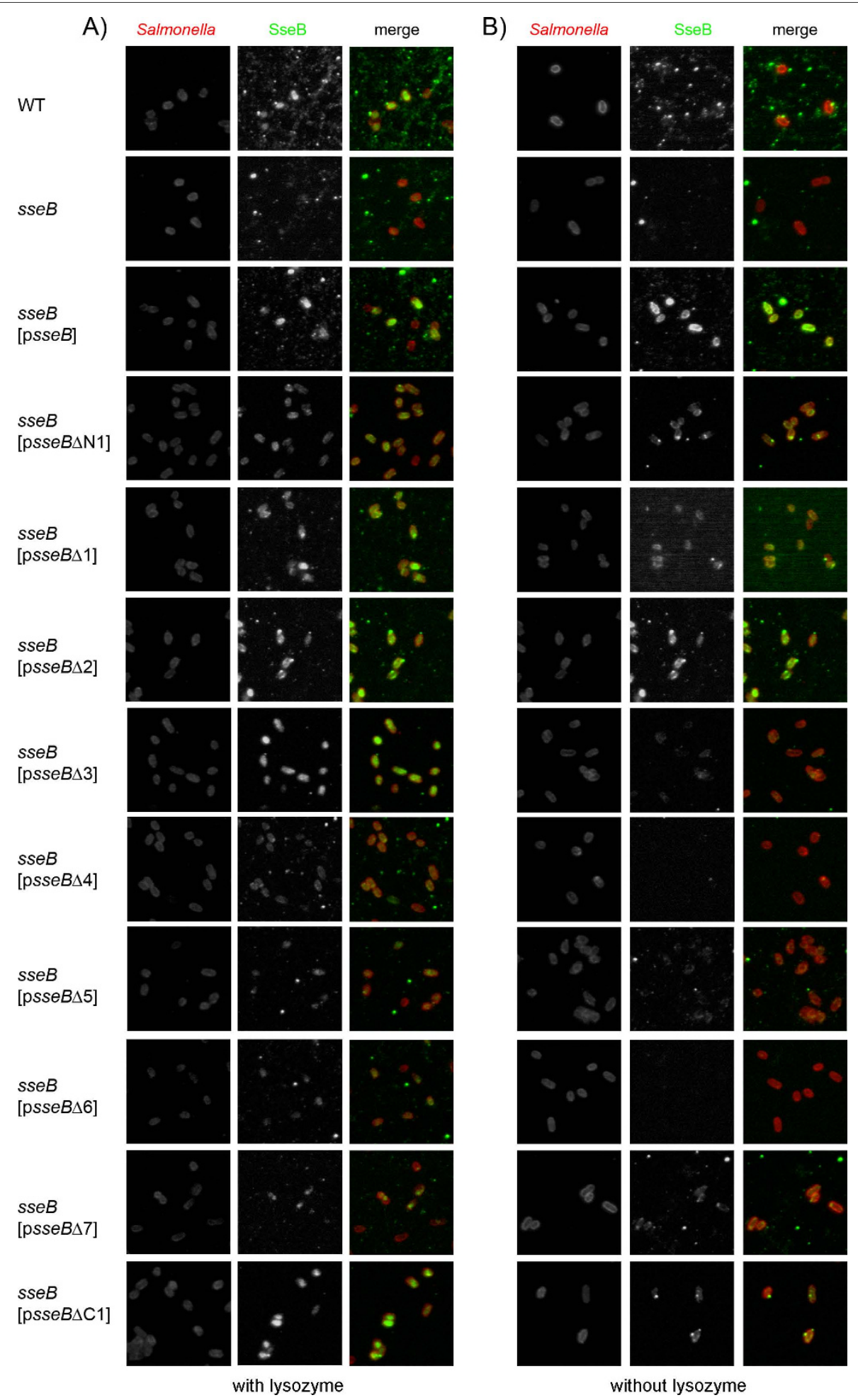

Figure 4 Surface location of SseB variants under in vitro culture conditions. S. Typhimurium wild type (WT), the sseB strain, or the sseB strain harboring psseB for expression of WT sseB, or plasmids for the expression of various mutant alleles of $s$ se $B(p s s e B \Delta x$ ) were grown in vitro under conditions that induced the synthesis and secretion of SseB. At $8 \mathrm{~h}$ of culture, the bacteria were fixed on chitosan-pretreated cover slips. The bacterial cells were stained with rabbit anti-Salmonella O-1,4,5,12,27 antiserum conjugated with DyLight 547 NHS ester (red). SseB was immuno-stained using rabbit polyclonal antibody against recombinant SseB as primary antibody and anti rabbit Alexa488 was used as secondary antibody (green). A) Presence of SseB within the bacterial cytoplasm was investigated by immunofluorescence labeling of SseB after lysozyme permeabilization of the bacteria. B) For analyses of SseB secretion and surface location, the lysozyme treatment was omitted. 
shown in Fig. 2. The investigation of surface-located SseB (Fig. 4B) indicated that WT SseB, SseB $\Delta \mathrm{N} 1$, SseB $\Delta 1$ and Sse $B \Delta C 1$ showed punctuate staining of single or low numbers of complexes per cell. A more intense and evenly distributed staining was observed for the psseB complemented $s s e B$ strain and a strains expressing $s s e B \triangle 2$. No or only very rare staining for $\mathrm{SseB}$ was found for the other mutant forms of SseB.

We next investigated the function of the various mutant forms of SseB in intracellular Salmonella (Fig. 5). The analyses of the synthesis of SseB variants were performed by immuno-staining of intracellular Salmonella after lysozyme treatment in order to allow antibody to access the non-secreted pool of SseB in the bacterial cytoplasm (Fig. 5A). SseB staining was observed in the cytoplasm of the WT strain and absent for the $s s e B$ strain. For $s s e B$ strains harboring plasmids for the expression of WT sseB or any of the mutant alleles of $s s e B$, signals in the bacteria were detected. However, the intensity of staining was different and rather weak labeling was observed for $\mathrm{SseB} \Delta 3$, $\mathrm{Sse} B \Delta 4$ and $\mathrm{SseB} \Delta 5$. Interestingly, in contrast to WT SseB that shows a homogenous distribution in the bacterial cytoplasm, we observed that SseB variants with deletions appeared to be concentrated at the poles of the bacterial cells (for example $\mathrm{SseB} \Delta 1$ and $\mathrm{SseB} \Delta \mathrm{N} 1$, Fig. $5 A)$. Previous work showed that $\mathrm{SseB}$ can be detected by immuno-gold labeling on the surface of intracellular Salmonella and that SseB-positive proteinaceous structures correlated with needle-like extensions that were detected in low copy number by electron microscopy [8]. The immuno-labeling of intracellular Salmonella was repeated but lysozyme treatment was omitted in order to specifically label the SseB-containing structures on the bacterial surface. Staining of intracellular Salmonella WT for SseB confirmed the presence of SseB-containing structures on the bacterial surface (Fig. 5B). Not all of the intracellular bacteria were positive for SseB and positive cells showed one or two punctuate signals. Signals for SseB were entirely absent for the $s s e B$ strain, but present in the $s s e B$ strain complemented with psseB. SseB-containing surface structures were very rare or not detectable in any of the $s s e B$ strains harboring plasmids for the expression of mutant alleles of $s s e B$. The observations suggest that although deletions of domains in SseB in part are compatible with secretion and binding to the bacterial surface in vitro, formation of SseB-containing surface structure on intracellular bacteria did neither tolerate the absence of any domain in SseB nor N- or C-terminal truncations.

\section{Deletional analyses of SseD}

We applied a similar deletion strategy to SseD. Based on the predictions of transmembrane regions (Fig. 6A; see also Additional file 2) and coiled-coil domains (Fig. 6B), variants of SseD were generated that lacked hydrophobic, putative TM domains, the coiled-coil domain, the chaperone-binding site or the $\mathrm{N}$ - or $\mathrm{C}$-terminal parts of the protein (Fig. 6C). In addition to episomal expression of mutated $s s e D$, exchange of the WT allele of $s s e D$ in the chromosome of Salmonella against mutant alleles was performed. The synthesis of $\operatorname{SseD} \Delta C 1, \operatorname{SseD} \Delta \mathrm{C} 2$ and SseD $\Delta$ C3 was observed if expressed by episomal genes, but not in strains with chromosomal deletions, likely due to lower expression levels. Synthesis of $\operatorname{SseD} \Delta \mathrm{N} 1$, $\operatorname{SseD} \Delta 1$ and $\operatorname{SseDC} \Delta 4$ was not detectable at all. We observed that the larger number of the deletion constructs was not secreted under in vitro conditions (Fig. 6D, Suppl. Fig. 1). Secretion was only detected for the constructs $\mathrm{SseD} \Delta 3$ and $\mathrm{SseD} \Delta 4$ that lacked hydrophobic domains in the central region of the protein. The presence of the mutant alleles on episomal elements or in the chromosome had no effect on the efficiency of secretion. We have not been able to detect surface structures containing SseD for WT or mutant strains using the antiserum against SseD (data not shown). These observations show that the integrity of the primary sequence of SseD is of critical importance for the secretion of the protein and more sensitive to alterations compared to SseB.

\section{Effect of deletions of domains in SseB or SseD on translocation of a SPI2-T3SS effector protein}

We tested the ability of Salmonella strains expressing WT or various deletion variants of SseB (Fig. 7A) or SseD (Fig. 7B) to translocate a representative substrate protein of the SPI2-T3SS. The use of an SseJ-Luc fusion protein has previously described for the quantification of the amounts of translocated effector protein. Here, the amount of translocated SseJ-Luc was determined by measurements of luciferase activities in lysates of infected cells. As expected from previous studies on the role of $\mathrm{SseB}$ in translocation, Luc activities in the background of the $s s e B$ strain were highly reduced, while reporter activities for the $s s e B$ strain complemented with psseB are similar to the levels for the WT strain. If the $s s e B$ strain was complemented with any of the deletion alleles of $s s e B$, highly reduced levels of reporter activity are observed in host cell lysates. For most strains, the reporter activities were indistinguishable from those of the $s s e B$ mutant strain. Only the Luc activities for strains expressing sse $B \triangle 2$ and $s s e B \Delta 3$ are slightly higher and reached about $20 \%$ of the activities of the WT strain.

For SseD, we observed that all deletions resulted in a reduction of the amount of translocated effector protein comparable to levels of the sseD strain. None of the strains harboring chromosomal deletions within sseD resulted in Luc activities higher than those of the sseD strain (Fig. 7B). 


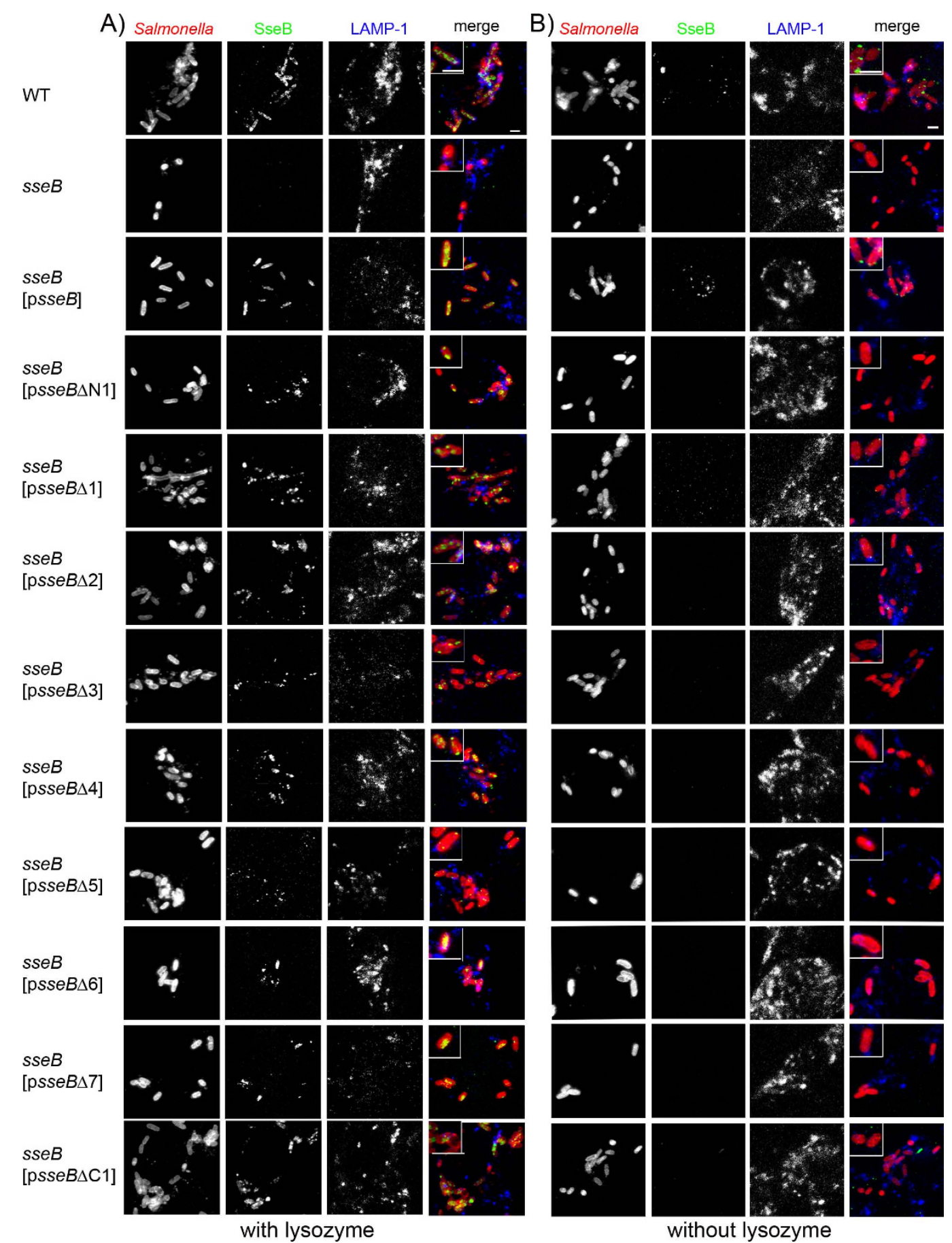

Figure $\mathbf{5}$ Synthesis secretion and translocon formation of SseB variants by intracellular Salmonella after infection of RAW macrophages. Macrophages were infected at a MOI of 25 with S. Typhimurium wild type (WT), the sseB strain, or the sseB strain harboring psseB for expression of WT $s s e B$ or plasmids for the expression of various mutant alleles of $s$ seB (psseB $\triangle \mathrm{x}$ ). At $6 \mathrm{~h}$ after infection, the infected cells were fixed with PBS containing $4 \%$ sucrose and $4 \%$ PFA and solubilized with $0.1 \%$ Triton X-100. SseB was immuno-stained using rabbit polyclonal antibody against recombinant SseB as primary antibody and anti rabbit Alexa488 was used as secondary antibody (green). S. Typhimurium was stained with rabbit anti-Salmonella O1,4,5,12,27 antiserum conjugated with Dylight 547 NHS ester (red). To control the intracellular localization of the bacteria, the late endosomal/lysosomal membrane marker LAMP-1 was immuno-stained using monoclonal antibody and Cy5-conjugated secondary antibody (blue). A) Presence of $\mathrm{SseB}$ within the bacterial cytoplasm was investigated by immunofluorescence labeling of SseB after lysozyme permeabilization of intracellular bacteria. B) For analyses of SseB secretion and translocon formation lysozyme treatment was omitted. Note the labeling of SseB in the bacterial cytoplasm for all strain except for the sseB strain in A) and the absence or rare occurrence of punctuated surface labeling for all strains except WT and sseB [psseB] in B). 
A)

transmembrane domain prediction

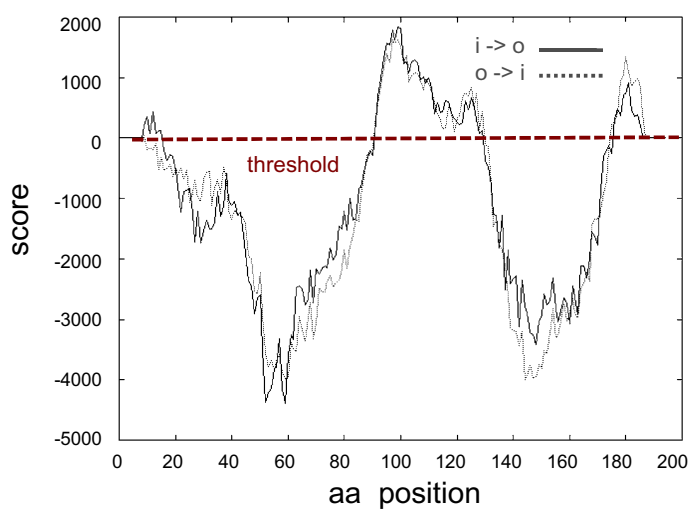

B) coiled-coil domain prediction

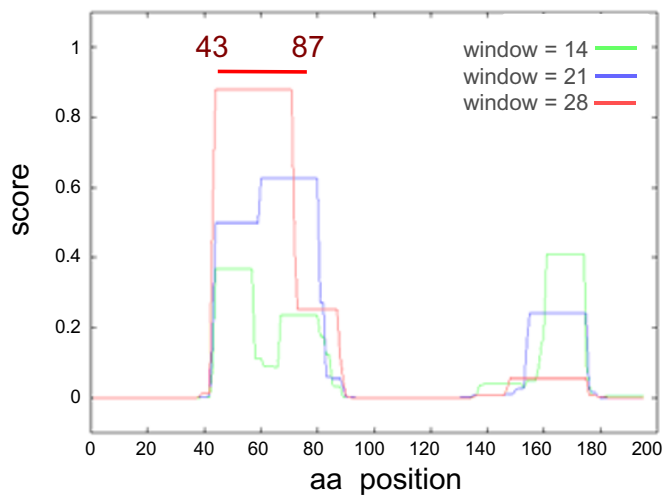

C)

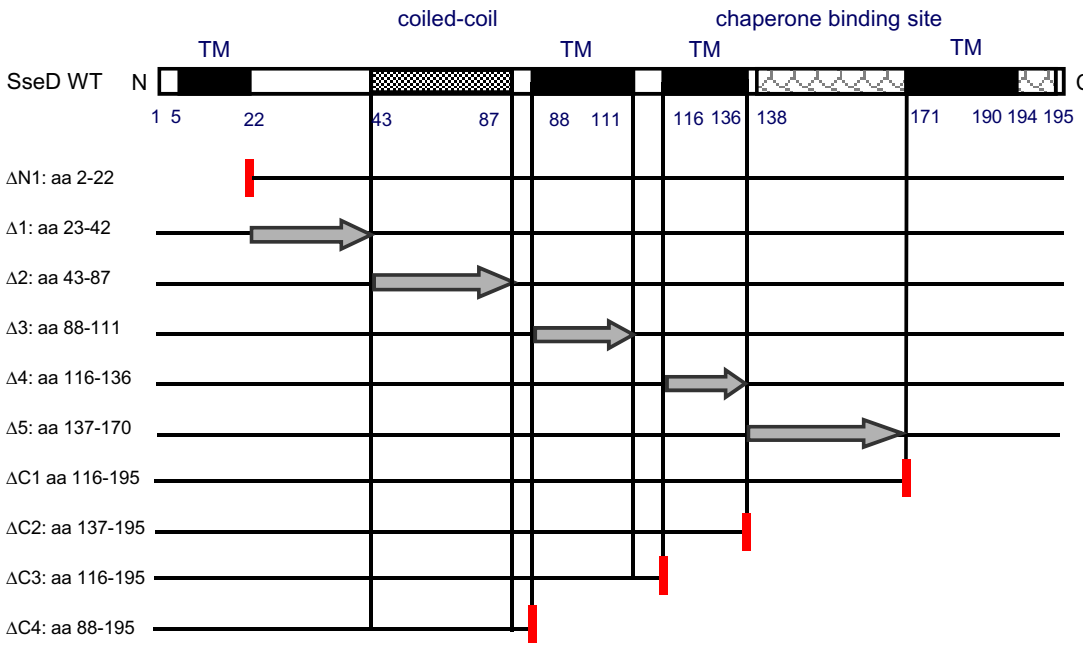

D)

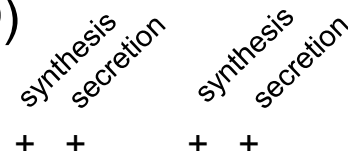

$+++$

$\begin{array}{lllll}- & - & & - & - \\ - & - & & - & - \\ + & - & + & - \\ + & + & + & + \\ + & + & + & + \\ + & - & & + & - \\ + & - & - & - \\ + & - & - & - \\ + & - & - & - \\ - & - & - & -\end{array}$

episomal chromosomal

Figure 6 Functional dissection of the putative translocon protein SseD. Predictions of transmembrane domains (A) and coiled-coil regions (B) in SseD were performed as described for Fig. 1. Four transmembrane regions and one coiled-coil region were predicted for SseD using TMpred and COILS. The chaperone binding site for SseA is located within the C-terminus of SseD [10]. C) The location of TM and coiled-coil regions in wild-type $\mathrm{SseD}$ is indicated and the positions of internal deletions are indicated by arrows. $\mathrm{N}$ - or C-terminal truncations are indicated by vertical red lines. Plasmid-borne mutant alleles were also integrated into the chromosome applying $\lambda$. Red recombineering recombined with positive selection [29]. D) Analyses of synthesis and secretion of SseD variants under in vitro conditions. For the in vitro studies, bacteria harboring wild-type SseD, chromosomal or plasmid-borne deletion variants of SseD were analyzed as described in Fig. $\mathbf{2}$. Secreted proteins were detached from the cell surface or directly recovered from the supernatant by precipitation with TCA and subjected to Western blot analyses using antiserum raised against SseD. The presents or absence of SseD in the bacterial lysate or secreted fractions (detached fraction or supernatant) is indicated as + or - . The analyses of synthesis and secretion of plasmid-encoded variants of SseD are shown in Additional file 2.

\section{Effect of deletions of domains in SseB or SseD on intracellular replication}

The effect of deletions in SseB or SseD on the intracellular replication in macrophages was quantified (Fig. 8). The intracellular replication of WT Salmonella and the complemented sseB strain was about 50- to 55-fold over a period of $14 \mathrm{~h}$. The replication of the $s s e B$ strain without plasmid or with plasmids for the expression of any of the deletions alleles of $s s e B$ was reduced to an about 5 -fold increase of the intracellular bacteria and no significant difference between the various constructs was observed (Fig. 8A). Similar characteristics were observed for strains 
A) SseB

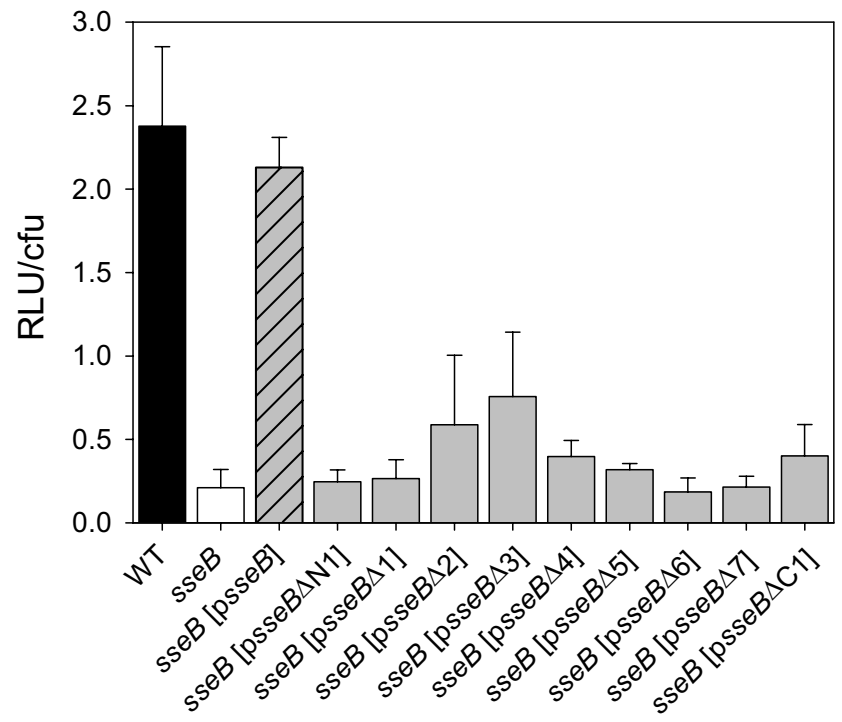

B) SseD

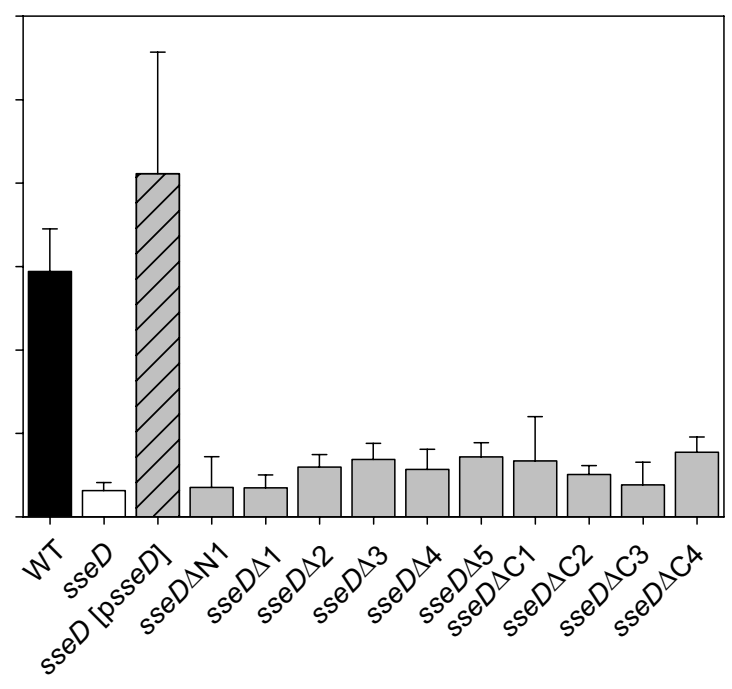

Figure 7 Effect of mutations in SseB or SseD on translocation of the SPI2 effector protein SseJ. Macrophages were infected at a MOl of 10 with S. Typhimurium wild type (WT), sseB, sseB [psseB] or sseB harboring plasmids for expression of various sseB mutant alleles (sseB [psseB $\triangle \mathrm{x}$ ]) (A), or WT, $s s e D$, sseD [psseD], or various strains harboring chromosomal deletion in $s s e D$ (B). All strains harbored a chromosomal translational fusion of the firefly luciferase to codon 200 of sseJ. At $8 \mathrm{~h}$ (B) or $14 \mathrm{~h}$ (A) post infection, the host cells were lysed and the numbers of intracellular bacteria were determined. The rest of the cell lysates were centrifuged and the luciferase activity (relative light units $=$ RLU) was measured in the supernatant in order to quantify the translocation of SseJ-Luc. The RLU per bacterium were calculated to compensate different replication rates of WT and the sseB mutant strains. Means and standard deviations of triplicate assays are shown and all experiments were performed at least twice.

expressing deletion alleles of $s s e D$ and none of the mutant strains showed intracellular replication that was above the level of the $s s e D$ strain (Fig. 8B).

These data indicate that SseB and SseD do not tolerate major alterations of the primary structure in order to fulfill their function as parts of the translocon of the SPI2T3SS. The data also demonstrate that a fully functional translocon is required for the efficient intracellular replication. The residual ability of strains expressing $s s e B \Delta 2$ or sse $B \Delta 3$ to translocate effector proteins appears to be insufficient to confer the ability of intracellular replication.

\section{Discussion}

In this study we performed a structure-based functional dissection of the SPI2-T3SS translocon proteins SseB and SseD. Protein domains predicted as putative transmembrane regions or coiled-coil regions were deleted, as well as $\mathrm{N}$ - or C-terminal portions, and previously defined binding regions for the specific chaperone SseA $[9,10]$.

The deletional and functional analyses described here clearly demonstrate the sensitivity of SseB and SseD against structural alterations. Many of the deletion variants lost the ability to be secreted by the SPI2-T3SS. However, we also identified a subset of deletion variants that were synthesized in quantities similar to the WT proteins, secreted under in vitro conditions and bound to the bacterial surface. The lack of the chaperone binding site in SseB led to reduced amounts of protein. We found that some mutant forms of SseB were on surface structures on bacteria grown in vitro (Fig. 4B), but not on intracellular Salmonella (Fig. 5B). Surface straining on intracellular bacteria was also absent for mutant forms of SseD. Although low levels of translocation of effector SseJ were possible in the presence of $\mathrm{SseB} \Delta 2$ (deletion of transmembrane domain) or SseB $\Delta 3$ (deletion of coiledcoil domain), the corresponding strains was as highly attenuated in intracellular replication as the $s s e B$ mutant strain. This observation may indicate that the temporally and spatially coordinated translocation of several effector proteins is required for proper intracellular proliferation. The various mutant forms of SseD were neither assembled into polar organelles on the surface of intracellular bacteria, nor functional in translocation of effector proteins or in supporting the intracellular replication of Salmonella in macrophages.

A current model for the assembly of the translocon proposes the formation of a hetero-oligomeric platform at the tip of the T3SS filament $[6,11]$. The subunits LcrV (Yersinia spp.) or IpaD (Shigella spp.) assemble such plat- 


\section{A) SseB}

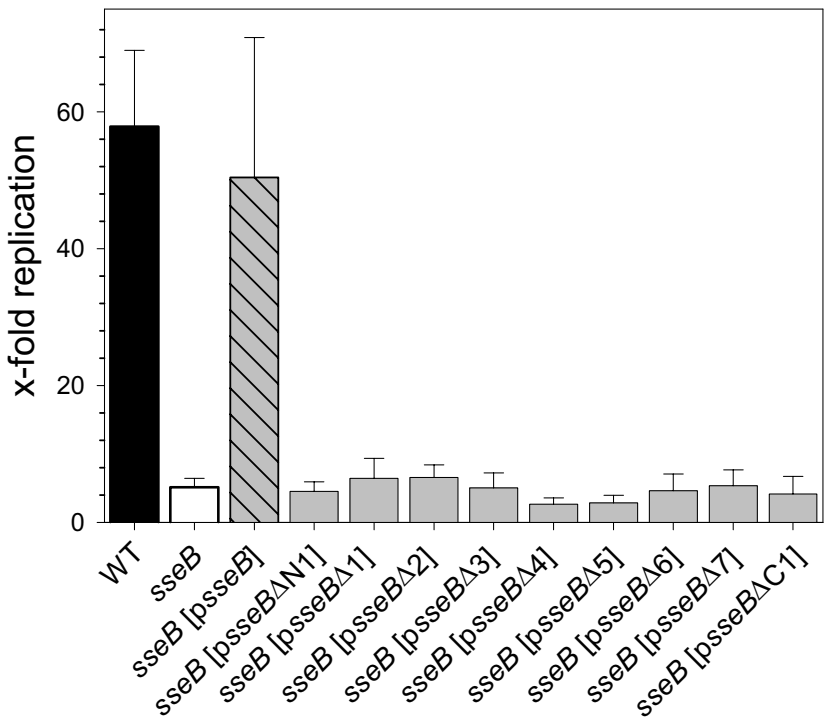

\section{B) SseD}

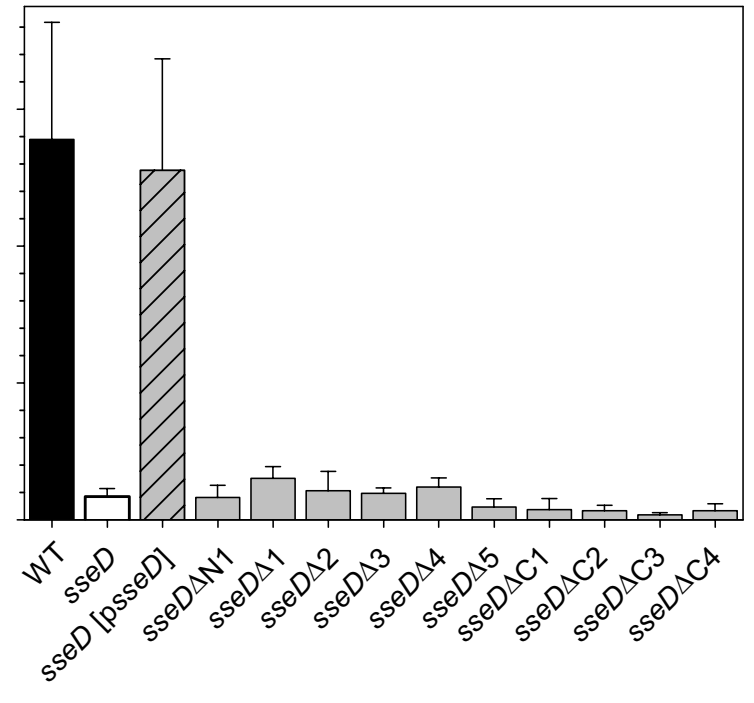

Figure 8 Effect of mutations in SseB or SseD on intracellular replication of Salmonella. Macrophages were infected at a MOI of 1 with S. Typhimurium wild type (WT), sseB, sseB [psseB] or sseB harboring plasmids for expression of various sseB mutant alleles (sseB [psseB $\triangle \mathrm{x}]$ ) (A), or WT, sseD, sseD [psseD], or various strains harboring chromosomal deletion in sseD (B). Extracellular bacteria were killed by gentamicin treatment during $1 \mathrm{~h}$ post infection. Intracellular bacteria were quantified after host cell lysis with Triton X-100 at $2 \mathrm{~h}$ and $16 \mathrm{~h}$ post infection. The $\mathrm{x}$-fold replication is the ratio of viable intracellular bacteria recovered at $16 \mathrm{~h}$ versus $2 \mathrm{~h}$ post infection. The replication rate was assessed in triplicates and the standard deviation of the mean was calculated. Means and standard deviations of triplicate assays are shown and all experiments were performed at least twice.

forms and based on sequence similarity, EspA of EPEC and SseB of the SPI2-T3SS are proposed to fulfill a similar function. LcrV, IpaD, SseB and EspA all harbor coiled-coil regions. The coiled-coil domain of EspA is essential for the assembly of the T3SS on the surface of EPEC [12]. In addition to function as a structural component of the translocon, EspA forms helical filaments [13], whereas a direct contribution of $\mathrm{SseB}$ to filament formation has not been observed. EspA filaments are thought to be optimized for the penetration of the mucus layer of the epithelium in order to establish contact with enterocytes for the translocation of effector proteins [13]. In contrast, the translocon of the SPI2-T3SS is assembled on bacteria within the SCV where no barrier might interfere with the insertion of the translocator pore into the target cell membrane. It was shown that $\mathrm{SseB}$ is present after secretion in a sheath-like structure on filamentous structures formed by the SPI2-T3SS in vitro [8]. Based on sequence similarity and previous functional characterization, $\mathrm{SseC}$ and $\mathrm{SseD}$ are likely to assemble the translocation pore of the SPI2-T3SS. We were not able to detect SseC on intracellular bacteria in the background of the various SseB deletion variants. In contrast, a defined punctuated staining for $\mathrm{SseC}$ was observed for WT and complemented sseB strain (data not shown). This indicates that mutations in SseB affect the organization of at least SseC on the surface of intracellular Salmonella. Further analysis of the tip of the SPI2-T3SS will require structural data for individual translocon proteins as well as for the oligomeric assembly of subunits $\mathrm{SseB}, \mathrm{SseC}$ and $\mathrm{SseD}$. Yet, the highly hydrophobic nature of $\mathrm{SseC}$ will impose serious limitations to biochemical approaches.

A functional dissection similar to our approach was performed by Chiu and Syu [14] for EspB from EHEC, the putative homologue of SseD. Although internal deletions and C-terminal truncations of similar extend to our deletions in SseD were generated, the effect of the mutations of EspB was far less dramatic and most mutant forms remained at least partial functions. To control if the loss of function phenotypes of $s s e D$ deletions were caused by the increased gene dosage due to episomal expression, deletion alleles were are also integrated in the native chromosomal context. However, SseD variants encoded by chromosomal alleles were also defective in the assembly of a functional translocation pore.

We propose that the function of the SPI2-T3SS of intracellular bacteria is more sensitive to structural alteration than the homologous components of T3SS of extracellular bacteria. Previous work revealed that only single or few copies of the T3SS exist and we assume that only these apparatuses mediated translocation [8]. In contrast, the T3SS systems of extracellular bacteria such as the EPEC LEE-T3SS, Salmonella SPI1-T3SS or Shigella Mxi/ Spa-T3SS exist in multiple copies [15-17]. If mutations 
result in a reduced function of the translocon, this may be compensated by the large number of active T3SS.

Further characterization of translocation pores inserted into target cell membranes could also involve the analyses of protein interaction by pull down experiments, as previous applied to EPEC EspB and EspD interaction using GST tags [18]. We observed that translocon proteins of the SPI2-T3SS did tolerate the C-terminal addition of HA-tag, but not of Strep-tag or larger tags, thereby restricting the analysis of protein interaction (data not shown).

Interestingly, translocon proteins involved in bacterial invasion exhibit several functions in addition to effector translocation, e.g. binding to caspase-1 (IpaB, SipB) [reviewed in [19]] or actin binding (SipC) [20]. A contribution to the adhesion to host cells has also been observed for translocon subunits of the EPEC T3SS [21] and the SPI1-T3SS of Salmonella [22]. So far, no additional functions have been assigned to the SPI2 translocon protein SseB, SseC, SseD. The role of these proteins appears to be restricted to the basal translocon function.

The Shigella translocon protein IpaC requires polar localization in the bacterial cytoplasm for its secretion during the invasion process [23]. We observed that WT SseB was distributed homogeneously in the cytoplasm of intracellular Salmonella. Additional staining at various time points after infection of macrophages did not indicate a polar distribution of non-secreted SseB and SseC in the bacterial cytoplasm (data not shown). Polarized localization within intracellular bacteria was only observed for SseB deletion variants with defective functions. These observations suggest that the features of translocon proteins involved in invasion are distinct from those required for intracellular activities. Shigella and invasive Salmonella possess a large number of T3SS copies distributed all over the bacterial surface $[15,16]$, but show a polar localization of the translocation complex $[23,24]$. In contrast, intracellular bacteria possess only one or few copies of the T3SS, but homogenous intracellular distribution of the translocon subunits [8]. The distribution of SseB may result from accumulation of redundant copies of $\mathrm{SseB}$ not required for translocon formation or may indicated a potential regulatory function on the expression or stability of other translocon subunits or effectors. The exact molecular mechanism behind this phenomenon has to be elucidated by future work.

\section{Conclusion}

Taken together, our functional dissection reveals that SPI2-T3SS proteins SseB and SseD require all the distinct protein domains we identified for its proper function in translocon formation. Future analyses of the important interface between an intracellular pathogen and its host cell will require the analyses of roles of individual amino acid residues in the interaction of subunits and function of translocon subunits in mediating translocation of effector proteins.

\section{Methods}

\section{Bacterial strains and growth conditions}

Salmonella enterica serovar Typhimurium (S. Typhimurium) NCTC 12023 was used as wild type and mutant strains derived from $S$. Typhimurium 12023 are listed in Table 1. For standard cultivation, strains were grown in 3 ml Luria-Bertani (LB) medium in a roller drum (TC-7, New Brunswick) at $37^{\circ} \mathrm{C}$. For the induction of expression of SPI2 genes and to trigger secretion by the SPI2-T3SS, minimal PCN-P media harboring phosphate starvation conditions at pH 5.8 was used. The minimal media contains $80 \mathrm{mM}$ morpholineethanesulfonic acid (MES), 4 $\mathrm{mM}$ Tricine, $100 \mu \mathrm{M} \mathrm{FeCl}_{3}, 376 \mu \mathrm{M} \mathrm{K}_{2} \mathrm{SO}_{4}, 50 \mathrm{mM} \mathrm{NaCl}$, $360 \mu \mathrm{M} \mathrm{K}{ }_{2} \mathrm{HPO}_{4} / \mathrm{KH}_{2} \mathrm{PO}_{4}$ (pH 5.8), 0.4\% glucose, $15 \mathrm{mM}$ $\mathrm{NH}_{4} \mathrm{Cl}, 10 \times$ micronutrients, $1 \mathrm{mM} \mathrm{MgSO}, 10 \mu \mathrm{M} \mathrm{CaCl}_{2}$ and has been described in detail before [25]. For pre-culture $\mathrm{PCN}+\mathrm{P}(25 \mathrm{mM}$ phosphate) medium at $\mathrm{pH} 7.4$, MES was replaced by morpholinepropanesulfonic acid (MOPS). If required, antibiotics carbenicillin or kanamycin were added to the various media at a concentration of $50 \mu \mathrm{g} \times \mathrm{ml}^{-1}$.

\section{Construction of mutant strains and plasmids}

For the chromosomal deletion of the open reading frames of $s s e B$ or $s s e D$, the 'one step inactivation' method of Datsenko and Wanner [26] was used. Following mutagenesis, the aph resistance cassette was removed by FLPmediated recombination. The oligonucleotides used for mutagenesis are listed in Additional file 3.

For quantitative analyses of SPI2 effector translocation, the reporter fusion $\mathrm{SseJ}_{200}$-Luc [27] was transferred into the sseB (MvP643) or sseD (MvP1129) deletion mutant via P22 transduction according to standard methods [28]. Plasmids used in this study are listed in Table 2.

The plasmids for complementation of $s s e B$ and $s s e D$ were generated as follows: The wild-type sequence of sse $B$ and the corresponding promoter region were amplified by PCR. The PCR product was purified using the Nucleotide removal kit (Qiagen), the purified DNA was digested by BamHI/EcoRV and cloned into the BamHI/ EcoRV digested low-copy vector pWSK30. Cloning of $s s e D$ was performed similarly but the gene under the control of its own promoter was cloned via EcoRI/XbaI restriction sites into pWSK29. The generated plasmids were sequenced and introduced into the corresponding mutant strain by electroporation. The primers for cloning as well as sequencing are shown in Additional file 3.

Plasmid-borne deletion alleles of the $s s e B$ or $s s e D$ were generated by a PCR-based method using the QuikChange 
Table 1: Salmonella strains used in this study

\begin{tabular}{|c|c|c|}
\hline Designation & relevant characteristics & Reference \\
\hline NCTC 12023 & wild type & lab collection \\
\hline MvP613 & sseJ $_{200}:: /$ luc aph & Gerlach et al. [27] \\
\hline MvP643 & $\Delta s s e B:: F R T$ & Red deletion, this study \\
\hline MvP723 & $\Delta s s e B:: F R T$ sseJ $_{200}:: / u c a p h$ & P22 of MvP613, this study \\
\hline MvP1129 & $\Delta s s e D:: F R T$ & Red deletion, this study \\
\hline MvP1125 & $\Delta s s e D::$ FRT sseJ ${ }_{200}:: / u c a p h$ & P22 of MvP613, this study \\
\hline MvP918 & $\Delta s s e D:: t e t A R$ & Red deletion, this study \\
\hline MvP1048 & $\Delta s s e D_{2-22^{*}}$ & Red deletion, this study \\
\hline MvP1049 & $\Delta s s e D_{23-42}$ & Red deletion, this study \\
\hline MvP1050 & $\Delta s s e D_{43-87}$ & Red deletion, this study \\
\hline MvP1051 & $\Delta s s e D_{88-111}$ & Red deletion, this study \\
\hline MvP1052 & $\Delta s s e D_{116-136}$ & Red deletion, this study \\
\hline MvP1053 & $\Delta s s e D_{137-170}$ & Red deletion, this study \\
\hline MvP1054 & $\Delta s s e D_{171-195}$ & Red deletion, this study \\
\hline MvP1055 & $\Delta s s e D_{137-195}$ & Red deletion, this study \\
\hline MvP1056 & $\Delta s s e D_{116-195}$ & Red deletion, this study \\
\hline MvP1057 & $\Delta s s e D_{88-196}$ & Red deletion, this study \\
\hline MvP1076 & $\Delta s s e D_{2-22}$ sseJ $_{200}:: l u c a p h$ & P22 of MvP613, this study \\
\hline MvP1078 & $\Delta s s e D_{23-42} s s e J_{200}:: / u c a p h$ & P22 of MvP613, this study \\
\hline MvP1080 & $\Delta s s e D_{43-87} s^{s e J_{200}:: I u c ~ a p h}$ & P22 of MvP613, this study \\
\hline MvP1082 & $\Delta s s e D_{88-111}$ sseJ $_{200}:: / u c a p h$ & P22 of MvP613, this study \\
\hline MvP1084 & $\Delta s s e D_{116-136}$ sseJ $_{200}:: / u c a p h$ & P22 of MvP613, this study \\
\hline MvP1086 & $\Delta s s e D_{137-170} s s e J_{200}::$ Iuc aph & P22 of MvP613, this study \\
\hline MvP1088 & $\Delta s s e D_{171-195} s_{s e J} J_{200}:: / u c a p h$ & P22 of MvP613, this study \\
\hline MvP1090 & $\Delta s s e D_{137-195}$ sseJ $_{200}:: / u c a p h$ & P22 of MvP613, this study \\
\hline MvP1092 & $\Delta s s e D_{116-195}$ sseJ $_{200}:: / u c a p h$ & P22 of MvP613, this study \\
\hline MvP1094 & $\Delta s s e D_{88-196}$ sseJ $_{200}:: / u c a p h$ & P22 of MvP613, this study \\
\hline
\end{tabular}

${ }^{*}$ subscript denotes the first and last codon of the deletion

II XL Site-Directed Mutagenesis Kit according to the instruction of the supplier (\# 200521-12, Stratagene, Heidelberg, Germany). All plasmids harboring mutant alleles were prescreened for successful mutagenesis, subsequently sequenced and introduced into the corresponding mutant strain by electroporation. Primers used for deletion, control PCR and DNA sequencing are listed in Additional file 3.

In order to move plasmid-borne sseD deletion alleles into the Salmonella chromosome, the $\lambda$ Red system was applied in combination with positive selection for the loss of a tetracycline resistance cassette on Bochner-Maloy plates as described previously [29]. For amplification of the mutations affecting the inner region of $s s e D$, the primer pair sseD-Del-Chrom-For and seq-rev were used. Fragments for deletions in the $5^{\prime}$ or $3^{\prime}$ region were ampli- fied using sseD-delN1-chrom-For in combination with seq-rev or sseD-Del-Chrom-For together with sseD-delC1 (2/3/4)-chrom-rev. All constructs were confirmed by sequencing. Sequences of primers used for deletion and sequencing are described in Additional file 3.

\section{Bioinformatics}

For bioinformatic predictions in terms of coiled-coil domains and transmembrane regions of the SPI2 translocon proteins SseB and SseD, the freely available service of the Swiss EMBnet node server http://www.ch.embnet.org:http://www.ch.embnet.org/software/

COILS form.html, http://www.ch.embnet.org/software/ TMPRED form.html was engaged. The sequence manipulation suite of the Bioinformatic Organisation http:// www.bioinformatics.org/sms/prot_mw.html was conducted in order to calculate the molecular weight of the 


\begin{tabular}{|c|c|c|}
\hline Designation & relevant characteristics & Reference \\
\hline pWSK29 & low copy number vector & lab stock \\
\hline pWSK30 & low copy number vector & lab stock \\
\hline p3232 & pWSK30, $P_{\text {sseA }}$ SseA sseB & this study \\
\hline p3320 & $\Delta s s e B_{15-30} *$ & p3232 derivative, this study \\
\hline p3321 & $\Delta s s e B_{38-57}$ & p3232 derivative, this study \\
\hline p3322 & $\Delta s s e B_{58-90}$ & p3232 derivative, this study \\
\hline p3323 & $\Delta s s e B_{38-90}$ & p3232 derivative, this study \\
\hline p3324 & $\Delta s s e B_{91-115}$ & p3232 derivative, this study \\
\hline p3325 & $\Delta s s e B_{116-136}$ & p3232 derivative, this study \\
\hline p3326 & $\Delta s s e B_{137-182}$ & p3232 derivative, this study \\
\hline p3327 & $\Delta s s e B_{2-14}$ & p3232 derivative, this study \\
\hline p3328 & $\Delta s^{\prime} B_{183-196}$ & p3232 derivative, this study \\
\hline p3281 & pWSK29, $P_{\text {sseA }} s s e D$ & this study \\
\hline p3329 & $\Delta s s e D_{2-22}$ & p3281 derivative, this study \\
\hline p3330 & $\Delta s s e D_{23-42}$ & p3281 derivative, this study \\
\hline p3331 & $\Delta s s e D_{43-87}$ & p3281 derivative, this study \\
\hline p3332 & $\Delta s s e D_{88-111}$ & p3281 derivative, this study \\
\hline p3333 & $\Delta s s e D_{116-136}$ & p3281 derivative, this study \\
\hline p3334 & $\Delta s s e D_{137-170}$ & p3281 derivative, this study \\
\hline p3335 & $\Delta s s e D_{171-195}$ & p3281 derivative, this study \\
\hline p3336 & $\Delta s s e D_{137-195}$ & p3281 derivative, this study \\
\hline p3337 & $\Delta s s e D_{116-195}$ & p3281 derivative, this study \\
\hline p3338 & $\Delta s s e D_{88-195}$ & p3281 derivative, this study \\
\hline
\end{tabular}

* subscript denotes the first and last codon of the deletion

SseB and SseD wild-type proteins as well as of the mutant variants of both proteins.

\section{Analyses of in vitro protein expression, surface attachment and secretion}

For the in vitro analyses of the expression, surface-attachment and secretion of SseB and SseD as well as the plasmid-borne or chromosomal derived mutant variants, the secretion assay described by Nikolaus et al. [7] was modified. Salmonella strains were pre-cultured overnight in $\mathrm{PCN}+\mathrm{P}\left(25 \mathrm{mM} \mathrm{P}_{\mathrm{i}}\right) \mathrm{pH}$ 7.4, diluted 1:50 in $400 \mathrm{ml} \mathrm{PCN}-\mathrm{P}$ media at $\mathrm{pH} 5.8$ and incubated $7 \mathrm{~h}$ in a shaker platform with agitation at $150 \mathrm{rpm}$ at $37^{\circ} \mathrm{C}$. For analyses of protein synthesis, aliquots of $1 \mathrm{ml}$ bacterial culture were pelleted by centrifugation in a table top centrifuge (Sigma 1-13) for $15 \mathrm{~min}$ at max. speed. The pellets were resuspended in sample buffer $(12.5 \%$ glycerol, $4 \%$ SDS, $50 \mathrm{mM}$ Tris$\mathrm{HCl} \mathrm{pH} \mathrm{6.8,2 \%} \beta$-mercaptoethanol, $0.01 \%$ bromophenol blue) according to the optical density $\left(\mathrm{OD}_{600}\right.$ of $1 \mathrm{ml}$ of culture $\times 100=\times \mu \mathrm{l}$ of sample buffer) and heated at $95^{\circ} \mathrm{C}$ for $5 \mathrm{~min}$. The remaining bacterial cultures were pelleted in a Sorvall RC5C centrifuge (ThermoFisher Scientific) at $6,000 \times \mathrm{g}$ for $30 \mathrm{~min}$ at $4^{\circ} \mathrm{C}$. For extraction of secreted proteins, the supernatant was passed through a $0.2 \mu \mathrm{m}$ Zap-cup sterile filter (10443401 Whatman Schleicher\&Schuell) and proteins were precipitated with trichloroacetic acid (TCA, 10\% [wt/vol] final concentration) over night at $4^{\circ} \mathrm{C}$. The pellet was resuspended in 20 $\mathrm{ml} \mathrm{PBS}$ in a $50 \mathrm{ml}$ centrifuge tube (Falcon, BD) and vigorously mixed on a Vortex mixer (Vortex Genie 2, Scientific Industries) for $60 \mathrm{~s}$ at full speed in order to recover cell surface attached proteins (detached fraction). Bacteria were harvested by centrifugation at $8,000 \times \mathrm{g} 30 \mathrm{~min}$ at $4^{\circ} \mathrm{C}$. Residual bacteria were removed by passing the supernatant through a $0.2 \mu \mathrm{m}$ filter (Corning) and proteins were precipitated with $10 \%$ [wt/vol] TCA over night at $4^{\circ} \mathrm{C}$. The TCA precipitates of the supernatant and the detached fraction were pelleted by centrifugation for 45 $\min$ at $10,000 \times \mathrm{g}$ at $4^{\circ} \mathrm{C}$. The pellet was washed twice with ice-cold acetone and recovered by centrifugation for $30 \mathrm{~min}$ at $10,000 \times \mathrm{g}$ at $4^{\circ} \mathrm{C}$. The final pellet was air dried, 
resuspended in $\times \mu$ l sample buffer corresponding to the volume of the pellet and heated at $95^{\circ} \mathrm{C}$ for $5 \mathrm{~min}$.

Expression, surface-attachment and secretion protein profiles of wild-type SseB or SseD and mutant variants, were analyzed by SDS-Page using Tris-Tricine gels (12\%) according to the method of Schägger and von Jagow [30]. For Western blotting, the semi-dry blotting procedure described by Kyhse-Andersen [31] was performed with slight modifications. The proteins were transferred onto $0.2 \mu \mathrm{m}$ nitrocellulose membranes (Schleicher \& Schüll) in Towbin buffer according to standard protocols [32].

For detection of SseB and SseD on Western blots, purified polyclonal rabbit antisera were used [7]. Mouse anti DnaK (Biotrend, Cologne, Germany) antibody was used to control equal loading of bacterial lysates as well as release of cytosolic protein into the detached fraction and the culture supernatant due to bacterial cell lysis. As secondary antibodies, horseradish peroxidase-conjugated goat anti-rabbit IgG and goat anti-mouse IgG (HRP, Jackson) were used. The blots were incubated for $1 \mathrm{~min}$ with Pierce ECL Western Blotting Substrate (32209, ThermoScientific) and exposed to X-ray films (Hyperfilm, GE, Freiburg, Germany).

\section{Cell culture and infection procedure}

For infection experiments, the murine monocyte cell line RAW264.7 was cultured in DMEM (E15-843, PAA, Pasching, Austria) supplemented with 10\% FCS (SigmaAldrich) and $2 \mathrm{mM}$ Glutamax (Invitrogen) at $37^{\circ} \mathrm{C}$ in $5 \%$ $\mathrm{CO}_{2}$ and $90 \%$ humidity. The cells were used for experiments up to passage number 25. Cells were seeded in 24 well plates (Greiner bio-one) one day before infection and allowed to duplicate. Bacteria were grown overnight at $37^{\circ} \mathrm{C}$ and stored at $4^{\circ} \mathrm{C}$ until use. Cultures were adjusted to $\mathrm{OD}_{600}=0.2$ (equivalent to $4 \times 10^{8}$ bacteria $\times \mathrm{ml}^{-1}$ ) in PBS and a master-mix of the bacteria in DMEM at a desired multiplicity of infection (MOI) was prepared directly prior infection. $300 \mu \mathrm{l}$ bacteria suspension was added per well. Bacteria were centrifuged onto the macrophages for $5 \mathrm{~min}$ at $500 \times \mathrm{g}$ and phagocytosis of the bacteria were allowed for $25 \mathrm{~min}$ at $37^{\circ} \mathrm{C}$. After infection, macrophages were washed two times with PBS and residual extracellular bacteria were killed by the addition of $100 \mu \mathrm{g} \mathrm{ml}^{-1}$ gentamicin dissolved in DMEM for $1 \mathrm{~h}$ at $37^{\circ} \mathrm{C}$. Subsequently, $15 \mu \mathrm{g} \times \mathrm{ml}^{-1}$ gentamicin in DMEM was added for the remaining infection period. Depending on the experiment, the infected cells were lysed or fixed various times points post infection as described below.

\section{Intracellular replication assay and quantitative analyses of SPI2 effector translocation}

In order to assess intracellular replication, $2 \times 10^{5}$ macrophages were seeded and a MOI of 1 was used for infection. $2 \mathrm{~h}$ and $16 \mathrm{~h}$ post infection, the infected cells were washed twice with PBS and lysed with $500 \mu \mathrm{l}$ of $0.1 \%$ Triton X-100 $10 \mathrm{~min}$ at RT. The lysates were adjusted to $1 \mathrm{ml}$ with PBS and serial dilutions were plated onto MH plates in order to determine the colony forming units (CFU) of viable bacteria. The $\mathrm{x}$-fold intracellular replication was defined by calculating the ratios of CFU counts at $16 \mathrm{~h}$ and $2 \mathrm{~h}$ after infection.

Quantification of intracellular SPI2 effector translocation was carried out as described previously [27]. Briefly, about $8 \times 10^{5}$ macrophages were infected with various Salmonella strains all harboring a chromosomal $\mathrm{Sse}_{200^{-}}$ luciferase reporter fusion protein at a MOI of $10.8 \mathrm{~h}$ and $14 \mathrm{~h}$ post infection, respectively, lysis of infected cells was performed for $15 \mathrm{~min}$ with shaking at RT using $100 \mu \mathrm{l}$ of eukaryotic lysis buffer (\#1669893, Roche). $10 \mu$ lysate was used for preparation of various dilution series in PBS that were plated onto $\mathrm{MH}$ plates in order to count intracellular cfu. The remaining lysate was centrifuged at maximal speed for $3 \mathrm{~min}$ in a table top centrifuge (1-13, Sigma). Triplicates of $25 \mu$ l supernatant were applied to 96 well microtiter plates (Microfluor, Dynatech) and $50 \mu \mathrm{l}$ luciferase reagent was added directly before the measurement was started. Luciferase activity of translocated SseJLuc effector protein was measured using a TopCount instrument (PerkinElmer) and expressed as Relative Light Units (RLU). The RLU per intracellular bacterium was calculated to adapt differences in replication.

\section{Immunofluorescence analyses of intracellular SseB expression and secretion}

For immuno-staining of SseB on the bacterial surface or within the bacterial cytosol after infection of macrophages the method of Schlumberger et al. [24] was applied. Briefly, macrophages were seeded on cover slips in 24 well plates at a density of $1 \times 10^{5}$ cells and infection was conducted at a MOI of $25.6 \mathrm{~h}$ post infection, the medium was removed and the infected macrophages were fixed directly with $4 \%$ para-formaldehyde (PFA) and $4 \%$ sucrose in PBS for 20 min at RT. Subsequently, the cells were washed three times with PBS, stored overnight in $4 \%$ sucrose in PBS and incubated in $20 \%$ sucrose in PBS for $10 \mathrm{~min}$ at RT. Following three washing steps with PBS, the cells were permeabilized with buffer A $(50 \mathrm{mM}$ EDTA, $20 \mathrm{mM}$ Tris-HCl, $1.8 \mathrm{~g} / \mathrm{l}$ glucose, $\mathrm{pH}$ 8.0) containing freshly added $0.1 \%$ Triton X-100 for $5 \mathrm{~min}$ at RT. Buffer A was replaced by three washing steps with buffer $B$ (10 mM EDTA, 25 mM Tris-HCl, $1.8 \mathrm{~g} / \mathrm{l}$ glucose, $\mathrm{pH}$ 8.0) and buffer $\mathrm{B}$ plus $5 \mathrm{~g} / \mathrm{l}$ lysozyme for staining of proteins in the bacterial cytosol or without lysozyme for staining of intracellular secreted proteins was added for $1 \mathrm{~h}$ at $4^{\circ} \mathrm{C}$. Cells were washed again with PBS and incubated for $1 \mathrm{~h}$ at RT in blocking solution (10\% goat serum, $1 \%$ bovine serum albumin, $4 \%$ sucrose in PBS). SseB was stained using polyclonal antisera against recombinant SseB from 
rabbit [7] and anti-rabbit Alexa488 (Molecular Probes, Invitrogen). $S$. Typhimurium was stained with rabbit antiSalmonella O1,4,5,12,27 antiserum (Difco) conjugated with DyLight 547 NHS ester (Pierce). The lysosome-associated membrane protein 1 (LAMP-1) that is associated with SCV in infected cells was stained using a monoclonal antibody H4A3 from rat (1:100, developed by J.T. August, J.E.K. Hildreth, was obtained from the Developmental Studies Hybridoma Bank developed under the auspices of the NICHD and maintained by The University of Iowa, Department of Biology, Iowa City, IA 52242) and anti rat Cy5 (1:500, Jackson). All antibodies were diluted in blocking solution. Following immuno-staining, the coverslips were mounted on Fluoprep (bioMèrieux) and sealed with Entellan (Merck). Images of the samples were recorded using a confocal laser-scanning microscope (Leica TCS-NT).

\section{Additional material}

Additional file 1 Effect of various deletions in sseD on synthesis and secretion of SseD in vitro. S. Typhimurium WT or $\triangle$ sseD without plasmid, harboring plasmid psseD for complementation of the sseD deletion, or plasmids for the expression of various sseD mutant alleles (psseD $\Delta \mathrm{x}$ ) were grown in $400 \mathrm{ml}$ minimal medium PCN-P $(0.4 \mathrm{mM})$ at pH 5.8 to induce SPI2 expression as well as protein secretion by the SPI2-T3SS. For analyses of protein synthesis, equal amounts of bacterial cells as adjusted by $\mathrm{OD}_{600}$ were harvested and resuspended in SDS-PAGE sample buffer (total cell fraction). Secreted protein bound to the bacterial surface was released by mechanical shearing and precipitated from bacteria-free supernatant (detached fraction) and secreted proteins in the supernatant were precipitated by addition of 10\% TCA (final concentration). For Western blot analysis, samples corresponding to equal amount of bacteria or supernatant were separated by SDS-PAGE and transferred to nitrocellulose membranes and protein was detected with antiserum raised against SseD. As loading control and control for cell lysis, the bacterial heat shock protein DnaK was detected. In total cell lysates, we observed a non-specific binding (indicated by the asterisk).

Additional file 2 Quantification of the effects of various deletions in sse $B$ on synthesis and secretion of $S s e B$ in vitro and on secretion and partitioning of SseD in vitro. The signals of Western blot shown in Fig. 2 for the secretion and partitioning of SseB and mutant variant and the West ern blot shown in Fig. 3 for the effector of deletions in SseB on secretion an partitioning of SseD were quantified. Densitometry was performed using ImageJ software http://rsbweb.nih.gov/ij/ and signal intensities were normalized to the total cell fraction set to $100 \%$.

Additional file $\mathbf{3}$ Oligonucleotides used in this study. The designation and sequence of oligonucleotides used for mutagenesis, strain construction and sequencing is shown.

\section{Authors' contributions}

SUH and MH designed experiments, SUH performed experimental work, SUH and $\mathrm{MH}$ analyzed data and wrote the manuscript. All authors read and approved the final manuscript.

\section{Acknowledgements}

This work was supported by the Deutsche Forschungsgemeinschaft grant HE1962/8-3. S.U.H. was a fellow the graduate school BIGSS 'Lead structures of cell function' of the Elite Network Bavaria. We like to thank Daniela Jäckel for excellent technical support of the work.

\section{Author Details}

Mikrobiologisches Institut, Universitätsklinikum Erlangen, Erlangen, Germany
Received: 11 August 2009 Accepted: 8 April 2010

Published: 8 April 2010

\section{References}

1. Gerlach RG, Hensel M: Protein secretion systems and adhesins: the molecular armory of Gram-negative pathogens. Int J Med Microbiol 2007, 297(6):401-415.

2. Galan JE, Wolf-Watz H: Protein delivery into eukaryotic cells by type III secretion machines. Nature 2006, 444(7119):567-573.

3. Haraga A, Ohlson MB, Miller SI: Salmonellae interplay with host cells. Nat Rev Microbiol 2008, 6:53-66.

4. Kuhle V, Hensel M: Cellular microbiology of intracellular Salmonella enterica: functions of the type III secretion system encoded by Salmonella pathogenicity island 2. Cell Mol Life Sci 2004, 61(22):2812-2826

5. Cornelis GR: The type III secretion injectisome. Nat Rev Microbio/ 2006, 4(11):811-825.

6. Mueller CA, Broz P, Cornelis GR: The type III secretion system tip complex and translocon. Mol Microbiol 2008, 68(5):1085-1095.

7. Nikolaus T, Deiwick J, Rappl C, Freeman JA, Schröder W, Miller SI, Hensel $M:$ SseBCD proteins are secreted by the type III secretion system of Salmonella pathogenicity island 2 and function as a translocon. $J$ Bacteriol 2001, 183(20):6036-6045.

8. Chakravortty D, Rohde M, Jäger L, Deiwick J, Hensel M: Formation of a novel surface structure encoded by Salmonella Pathogenicity Island 2. EMBO J 2005, 24(11):2043-2052.

9. Zurawski DV, Stein MA: The SPI2-encoded SseA chaperone has discrete domains required for SseB stabilization and export, and binds within the C-terminus of SseB and SseD. Microbiology 2004, 150(Pt 7):2055-2068.

10. Zurawski DV, Stein MA: SseA acts as the chaperone for the SseB component of the Salmonella Pathogenicity Island 2 translocon. $\mathrm{Mol}$ Microbiol 2003, 47(5):1341-1351.

11. Veenendaal AK, Hodgkinson JL, Schwarzer L, Stabat D, Zenk SF, Blocker AJ: The type III secretion system needle tip complex mediates host cell sensing and translocon insertion. Mol Microbio/ 2007, 63(6):1719-1730.

12. Delahay RM, Knutton S, Shaw RK, Hartland EL, Pallen MJ, Frankel G: The coiled-coil domain of EspA is essential for the assembly of the type III secretion translocon on the surface of enteropathogenic Escherichia coli. J Biol Chem 1999, 274(50):35969-35974.

13. Daniell SJ, Takahashi N, Wilson R, Friedberg D, Rosenshine I, Booy FP, Shaw RK, Knutton S, Frankel G, Aizawa S: The filamentous type III secretion translocon of enteropathogenic Escherichia coli. Cell Microbiol 2001, 3(12):865-871

14. Chiu HJ, Syu WJ: Functional analysis of EspB from enterohaemorrhagic Escherichia coli. Microbiology 2005, 151(Pt 10):3277-3286.

15. Blocker A, Gounon P, Larquet E, Niebuhr K, Cabiaux V, Parsot C, Sansonetti $P$ : The tripartite type III secreton of Shigella flexneri inserts IpaB and IpaC into host membranes. J Cell Biol 1999, 147(3):683-693.

16. Kubori T, Matsushima Y, Nakamura D, Uralil J, Lara TM, Sukhan A, Galan JE, Aizawa SI: Supramolecular structure of the Salmonella typhimurium type III protein secretion system. Science 1998, 280(5363):602-605.

17. Knutton S, Rosenshine I, Pallen MJ, Nisan I, Neves BC, Bain C, Wolff C, Dougan G, Frankel G: A novel EspA-associated surface organelle of enteropathogenic Escherichia coli involved in protein translocation into epithelial cells. EMBO J 1998, 17:2166-2176.

18. Ide T, Laarmann S, Greune L, Schillers H, Oberleithner H, Schmidt MA: Characterization of translocation pores inserted into plasma membranes by type III-secreted Esp proteins of enteropathogenic Escherichia coli. Cell Microbiol 2001, 3(10):669-679.

19. Navarre WW, Zychlinsky A: Pathogen-induced apoptosis of macrophages: a common end for different pathogenic strategies. Cell Microbiol 2000, 2(4):265-273

20. Hayward RD, Koronakis V: Direct nucleation and bundling of actin by the SipC protein of invasive Salmonella. EMBO J 1999, 18(18):4926-4934.

21. Cleary J, Lai LC, Shaw RK, Straatman-Iwanowska A, Donnenberg MS, Frankel G, Knutton S: Enteropathogenic Escherichia coli (EPEC) adhesion to intestinal epithelial cells: role of bundle-forming pili (BFP), EspA filaments and intimin. Microbiology 2004, 150(Pt 3):527-538,

22. Lara-Tejero M, Galan JE: Salmonella enterica serovar typhimurium pathogenicity island 1-encoded type III secretion system translocases 
mediate intimate attachment to nonphagocytic cells. Infect Immun 2009, 77(7):2635-2642.

23. Jaumouille V, Francetic O, Sansonetti PJ, Tran Van Nhieu G: Cytoplasmic targeting of IpaC to the bacterial pole directs polar type III secretion in Shigella. EMBO J 2008, 27(2):447-457.

24. Schlumberger MC, Muller AJ, Ehrbar K, Winnen B, Duss I, Stecher B, Hardt WD: Real-time imaging of type III secretion: Salmonella SipA injection into host cells. Proc Natl Acad Sci USA 2005, 102(35):12548-12553.

25. Deiwick J, Nikolaus T, Erdogan S, Hensel M: Environmental regulation of Salmonella pathogenicity island 2 gene expression. Mol Microbiol 1999, 31(6):1759-1773.

26. Datsenko KA, Wanner BL: One-step inactivation of chromosomal genes in Escherichia coli K-12 using PCR products. Proc Natl Acad Sci USA 2000, 97(12):6640-6645.

27. Gerlach RG, Hölzer $S U$, Jäckel $D$, Hensel M: Rapid engineering of bacterial reporter gene fusions by using Red recombination. Appl Environ Microbiol 2007, 73(13):4234-4242.

28. Maloy SR, Stewart VL, Taylor RK: Genetic analysis of pathogenic bacteria. Cold Spring Harbor, New York: Cold Spring Harbor Laboratory Press; 1996.

29. Karlinsey JE: $\lambda$-Red genetic engineering in Salmonella enterica serovar Typhimurium. Methods Enzymol 2007, 421:199-209.

30. Schägger $\mathrm{H}$, von Jagow $\mathrm{G}$ : Tricine-sodiumdodecyl sulfatepolyacrylamide gel electrophoresis for the separation of proteins in the range of 1-100 kDa. Anal Biochem 1987, 266:368-379.

31. Kyhse-Andersen J: Electroblotting of multiple gels: a simple apparatus without buffer tank for rapid transfer of proteins from polyacrylamide to nitrocellulose. J Biochem Biophys Methods 1984, 10(3-4):203-209.

32. Ausubel FM, Brent R, Kingston RE, Moore DD, Seidman JG, Smith JA, Struhl K: Current protocols in molecular biology. New York: Wiley; 1987.

\section{doi: $10.1186 / 1471-2180-10-104$}

Cite this article as: Hölzer and Hensel, Functional dissection of translocon proteins of the Salmonella Pathogenicity Island 2-encoded type III secretion system BMC Microbiology 2010, 10:104

Submit your next manuscript to BioMed Central and take full advantage of:

- Convenient online submission

- Thorough peer review

- No space constraints or color figure charges

- Immediate publication on acceptance

- Inclusion in PubMed, CAS, Scopus and Google Scholar

- Research which is freely available for redistribution

Submit your manuscript at www.biomedcentral.com/submit
C Biomed Central 